NASA Technical Memorandum 108979

$$
\begin{gathered}
150547 \\
P_{1} 11
\end{gathered}
$$

\title{
NASA Scientific and Technical Program - User Survey
}

\author{
J.F. Hunter and C.W. Shockley
}

(NASA-TM-108979) NASA SCIENTIFIC ANO TECHNICAL PROGRAM: USER SURVEY (NASA) $11 \mathrm{P}$

Unc las

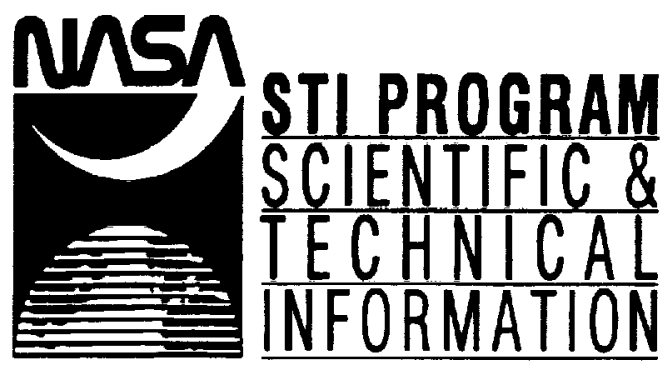





\title{
NASA SCIENTIFIC AND TECHNICAL PROGRAM — USER SURVEY
}

\author{
Judy F. Hunter \\ Scientific and Technical Information Program \\ NASA Headquarters \\ Washington, DC \\ Cynthia W. Shockley \\ Logistics Management Institute \\ Bethesda, Maryland
}

\begin{abstract}
An intensive user requirements survey was undertaken by NASA's Scientific and Technical (STI) Program to improve the foundation for its user outreach program and in response to the STI Council. For this investigation, the definition of STI encompasses textual, graphic, numeric, image, audio, or video information produced domestically and internationally. Between January and April 1992, 550 NASA scientists, engineers, and contractors were personally interviewed. Another 650 individuals responded to a mailed out questionnaire. User requirements data were collected on use of NASA's STI publications assistance program for producing STI, as well as access to STI through the use of people, printed, and electronic resources, both internal and external to the NASA STI Program. To analyze the user demographics data, a database was built, used for analysis, and will be used for ongoing analysis by the NASA STI Program.
\end{abstract}

\section{What is NASA's Scientific and Technical In- formation Program?}

As defined by the Scientific and Technical Information Program of NASA Headquarters, scientific and technical information (STI) is the collected set of facts resulting from scientific, technical, and related engineering research and development efforts. It includes information from both basic and applied research in the entire range of scientific disciplines. STI encompasses text, numeric data, graphics, images, audio, and video information. It is obtained from experiments, observations, instruments, or computers. STI is produced domestically and internationally.

The NASA STI Program was established to provide STI management and services as a part of the agency's mission as stated in the National Aeronautics and Space Act of 1958 (P.L. 85-568). That Act charged NASA with the responsibility to "provide for the widest practicable and appropriate dissemination of information concerning its activities and the results thereof." Since that time the STI Program has grown to address three major areas:

- STI Program Products which include announcement publications, current awareness products, STI handbooks and tools, NASA technical report series, and continuing and special bibliographies. Representative publications are STAR (Scientific and Technical Aerospace Reports) and SCAN (Selected Current Aerospace Notices).

- STI Program Services which include reference and literature services, training, translations, online assistance, microfiche and hardcopy document supply services, document distribution subscription services, and current awareness services.

- STI Publications Assistance which supports researchers in publishing their work by providing for all aspects of the production process including editing, graphics, reproduction, and printing.

The core system for these products and services is RECON (Research Connection) - the large-scale, online information retrieval database. This system, begun in 1968, is now used for over 75,000 searches annually, is accessible from terminals worldwide, and contains over three million bibliographic citations. RECON is operated on a day-to-day basis by the Center for AeroSpace Information (CASI). Here new STI arrives in all media from a variety of sources, is reviewed and 
analyzed, and incorporated into RECON. CASI also films all NASA-supported reports to produce microfiche copies for distribution. There are also several STI Program services available, such as technical translation services and customized bibliographies.

The NASA STI Program maintains operations at Headquarters and each of the 10 NASA Centers. Each Center is responsible for ensuring that reports from NASA employees and contractors are introduced into the STI system. The Centers provide NASA employees with publishing support, technical library services, and multimedia presentations. Center STI staff employ all available products and services to serve their users. Center libraries contribute to the Aerospace Research Information Network (ARIN) database which is the union list of NASA library holdings. ARIN also serves as the integrated library system supporting other functional areas; such as, shared cataloging, bibliographic searching, circulation, interlibrary loan, and management information.

Thus, the STI Program provides users access to a massive flow of STI which represents the largest collection of aeronautical and space science information in the world. The STI Program's goal is to provide relevant and timely STI products and services for its users - NASA scientists, engineers, managers, and NASA contractors, other government agencies and their contractors, universities throughout the world, international partners, and the general public.

\section{AKey Issue: What Role is the NASASTI Brogram Playing?}

In the winter of 1990, the STI Program of NASA Headquarters directed that a study be undertaken to update their understanding of users' requirements for its products and services. In April 1991, the NASA STI Council, chaired by Dr. Leonard A. Harris, was formed as an internal committee to provide impartial advice and counsel on the STI Program. Membership of the Council is provided representatively by individuals from Headquarters, a Research Center, a Flight Center, and Goddard Space Flight Center or the Jet Propulsion Lab (JPL). The Council is composed of senior NASA employees who are able to speak authoritatively and have a broad under- standing of NASA's STI needs and concerns, and those of the aerospace community at large.

The Council began reviewing overall STI issues. The major issues were to understand better the STI user community, determine user requirements, and identify improvements for products and services provided by the STI Program. The original study directed by the STI Program was refocussed to address the following questions raised by the Council:

- Who are the STI Program users?

- What are the products and services used across the NASA Centers?

- Who are the frequent users and why?

- Who are the infrequent or nonusers and why?

- What are the users' suggestions for improvements?

The Council requested a briefing in one year on results of a survey conducted to answer their questions. That meeting, set for May 1992, would provide the Council with needed insights into requirements that NASA users have for STI products and services.

\section{How to Determine NASA's Requirements for STI?}

An STI Team was formed to implement a plan to answer the Council's directives. The Team was composed primarily of staff from Headquarters and two Federally-Funded Research and Development Centers - Logistics Management Institute and MITRE. Major contributions to the STI Team were provided also by Headquarters and Center STI Managers and staffs.

To acquire data for the study, the team determined the need for three survey phases:

- Phase I: Pretest of survey instrument at selected sites

- Phase II: One-on-one surveys conducted by Center STI staff

- Phase III: Mail back questionnaires.

The team drafted a preliminary survey instrument in October 1991 and discussed it with STI Managers and staff of each Center via teleconfe- 
ence. For Phase I, a revised version of the survey instrument was pretested at three NASA sites Langley, Goddard, and Headquarters. These three sites were selected for their proximity to Washington, DC and their representativeness of all NASA sites. Thirty-three pretest interviews were conducted in November 1991. Phase I participants were selected representatively from major NASA functional areas, i.e., research, development, test and evaluation, and management/administration.

The survey instrument was revised significantly to reflect experience gained during the pretest. The revised instrument was presented to NASA STI Managers and their staffs during a second teleconference on January 7, 1992. After the teleconference, final adjustments were made to the survey instrument, and it became the foundation for collecting STI user requirements data.

The final survey instrument had five sections:
I. STI User Background
II. STI Production
III. Access to STI
IV. Use of Additional STI Program Services
V. Opinions Regarding the Overall NASA STI Program.

The first section gathered demographic data about each user. These data allowed the team to learn about a user's professional disciplines, work roles, levels of education, continuing education, length of service with NASA, status as a NASA employee or contractor, association with a specific NASA program or project, previous position held, and participation in professional societies and other associations. These data allowed an examination of the demographic variables associated with frequent and infrequent users when undertaking later analysis.

The second and third sections were designed to elicit relevant feedback on how NASA staff use STI publications assistance capabilities, products, and services. The fourth section examined use of CASI-generated products and services. The last section gathered free text responses to questions regarding overall familiar- ty with the STI Program, suggestions for new products and services, improvements to existing products and services, and willingness to participate in a user's group for defining the future NASA STI Program.

The final survey instrument was distributed to the STI Managers at Headquarters and at each Center. Copies were made and the one-onone interviews (Phase II) begun. This final instrument was adapted into a self-administered mail back questionnaire used in Phase III. Explanatory notes were incorporated throughout the questions to facilitate self-administration. Graphic representations of the title pages of some of the STI products were portrayed to heighten recognition for individuals who might not be familiar with them.

\section{How the Survey Instruments and Ques- tionnaires Were Used}

To address the concerns of the STI Council, a methodology for identifying both frequent and infrequent users had to be determined. Frequent users would be identified by the STI Program located at each NASA Center since staff there would be familiar with those individuals who routinely requested and used STI products and services. Based on data obtained from the NASA Headquarters Personnel Office, the total population of government scientists and engineers was given as 10,385 . A projected sample size needed from each Center, in order to obtain a confidence level of 95 percent in the surveyed results for frequent users, was determined. The number of individuals from each Center for Phase II interviews are shown in Table 1.

The individuals who were difficult to identify were those persons who did not come to the library, who were not on the mailing list for STI products, or did not have a RECON account. A random distribution approach, known as Phase III survey administration, was determined to be the most effective way to approach infrequent users of STI products and services and to learn of their requirements. A database for random sampling across all Centers for identifying infrequent users was prepared using machine-readable telephone books acquired from each Center. Although this approach also would contact users of 
the STI Program, there was no other methodology available, given the time constraints of the study. For obvious reasons, the following groups were deleted from the database and did not participate in Phase III:

- Frequent users identified by the Centers for Phase II interviews

- Participants interviewed by Dr. Thom Pinelli in the earlier NASA STI Program user satisfaction assessment survey

- Staff from NASA Directorates and Offices not typically in need of STI, e.g., Personnel, Budget and Finance, and Security

- STI Program staff at a NASA Center

- Members of the STI Council.

\begin{tabular}{|l|c|}
\hline NASA Center & $\begin{array}{l}\text { Number Of Re- } \\
\text { quested Phase II } \\
\text { Interviews }\end{array}$ \\
\hline Headquarters & 5 \\
\hline Ames & 45 \\
\hline Goddard & 70 \\
\hline Johnson & 50 \\
\hline JPL & 50 \\
\hline Kennedy & 45 \\
\hline Langley & 45 \\
\hline Lewis & 60 \\
\hline Marshall & 80 \\
\hline Stennis & 5 \\
\hline TOTAL & 455 \\
\hline
\end{tabular}

Table 1.

To achieve a high confidence level, the tearn's goal was to have 2,500 completed Phase III questionnaires returned. Based on a 30 percent rate of return, more than 7,400 NASA employees and contractors were randomly selected from this database to receive the Phase III questionnaire. Each Center was represented proportionally in the selected group. In addition, more than $\mathbf{5 0}$ former users of STI products and services, i.e., individuals who had dropped their RECON accounts in the last two years, also received a Phase III questionnaire. Table 2 shows the sample size and number of Phase III questionnaires distributed per Center.

\section{Survey Administration}

Phase II involved in-depth one-on-one (or small group) interviews conducted by NASA Center STI Program staff with individuals who were identified as frequent users of STI products and services. These interviews were conducted from mid-January through early March 1992 at all NASA sites. Based on experience gained during the pretest, an STI Council User Suroey Interview Plan and Guide was prepared. This Guide was briefed to the Center STI Managers and staff during the January 7, 1992 teleconference, then made available to them. The Guide provided background on Phase II sampling methodology, estimates for the interview workload imposed on the Center staff, and hints for conducting interviews.

The concurrent Phase III activity was a mail-back self-administered questionnaire distributed randomly to NASA staff and contractors. Representative samples were drawn from each Center, and the Phase III questionnaires were distributed using the NASA internal pouch mail system. The brochure What is NASA's Best Kept Secret? which highlighted the STI Program for individuals not familiar with its products and services accompanied each questionnaire. Once completed, the questionnaire was returned via the pouch mail system, directly to the STI Program office.

To further assist both phases of survey administration, a voice mail number was established. This STI Council User Survey Response Line allowed anyone participating in the study to call and leave a message of any length. Calls were returned within one work day.

\section{How the Large Volume of Survey Data was Handled}

Features selected for a software package that would support data analysis of the STI Council survey were:

- Relational data model

- Easy-to-use data entry

- Easy-to-use query capabilities

- Support for multiple data types (character and numeric) 


\begin{tabular}{|l|c|c|}
\hline \multicolumn{1}{|c|}{ NASA Center } & $\begin{array}{l}\text { Sample Size Need- } \\
\text { ed For High Con- } \\
\text { fidence Level }\end{array}$ & $\begin{array}{l}\text { Sample Size For } \\
\text { Phase III Ques- } \\
\text { tionnaire Distri- } \\
\text { bution }\end{array}$ \\
\hline Headquarters & 14 & 42 \\
\hline Ames & 285 & 855 \\
\hline Goddard & 320 & 960 \\
\hline Johnson & 297 & 891 \\
\hline JPL & 285 & 855 \\
\hline Kennedy & 285 & 855 \\
\hline Langley & 294 & 882 \\
\hline Lewis & 306 & 918 \\
\hline Marshall & 327 & 981 \\
\hline Stennis & 76 & 228 \\
\hline Totals & 2,489 & 7,467 \\
\hline
\end{tabular}

Table 2.

- Support for creating virtual tables or views across files

- Easy-to-use report generation

- Import/export capabilities.

The personal computer ( $\mathrm{PC}$ )-based database software package FoxPro ${ }^{\mathrm{TM}}$ was selected for use in creating the Phase III infrequent user sample database and for recording both Phase II and III data. A menu and mouse-driven data entry system was developed which mirrored the Phase II and Phase III survey instruments. Data were input quickly into the FoxPro database so that interim reviews of survey results could be taken. The FoxPro ${ }^{\mathrm{TM}}$ feature "query-by-example" was employed to generate tables and statistical analyses.

Another database package, InMagic ${ }^{\mathrm{TM}}$, was used to record and analyze full-text responses to a number of opinion-gathering questions. Responses to questions such as "What new products or services would you like the STI Program to offer?" were varied, but fell into discernible patterns. Using InMagic ${ }^{\mathrm{TM}}$, text responses were coded into response categories. These categories were adapted to the FoxPro'TM input system. Later, data for such opinion questions could be reviewed in comparable response groupings using FoxProtM, although the full text was retained for continued in-context analysis.

\section{Survey Results Pointed to Challenges for the NASASTI Program}

Center STI Staff conducted 550 Phase II surveys. This figure exceeded the requested number. Approximately 650 Phase III questionnaires were received back and entered into the database. This number reflected only one-quarter of the goal for responses the team wanted to obtain. However, as a response rate of almost nine percent, i.e., 650 responses out of 7,500 distributed questionnaires, it was viewed as a normal rate of return for such endeavors. The study schedule did not permit follow-ups with recipients of the Phase III questionnaires. This step might have increased the response rate.

All data received in Phases II and III were captured in the database, but not all of these data were used to prepare for the STI Council briefing. Analysis at that time was limited to data needed to prepare for that briefing (see questions posed by the Council in Section II). 


\section{A. Respondents' Backprounds}

Each respondent had the opportunity to
Based on how often a respondent used STI Publications Assistance Services the team was able to place him or her in a frequent, moderate, or infre-

\begin{tabular}{|l|l|l|l|l|l|l|}
\hline $\begin{array}{l}\text { Dominant } \\
\text { Disciplines }\end{array}$ & $\begin{array}{l}\text { Aerospace } \\
\text { Engineering } \\
(15 \%)\end{array}$ & $\begin{array}{l}\text { Computer } \\
(8 \%)\end{array}$ & $\begin{array}{l}\text { Electrical En- } \\
\text { gineering } \\
(7 \%) \\
\text { Mechanical } \\
\text { Engineering } \\
(7 \%)\end{array}$ & $\begin{array}{l}\text { Aeronautic } \\
\text { Engineering } \\
(5 \%)\end{array}$ & $\begin{array}{l}\text { Space Science } \\
(4 \%) \\
\text { Propul- } \\
\text { sion/Power } \\
(4 \%) \\
\text { Data Systems } \\
(4 \%) \\
\text { Physics (4\%) }\end{array}$ & $\begin{array}{l}\text { Flight Sys- } \\
\text { tems (3\%) } \\
\text { Measure- } \\
\text { ment/Instru- } \\
\text { mentation } \\
(3 \%)\end{array}$ \\
\hline $\begin{array}{l}\text { Dominant } \\
\text { Work Roles }\end{array}$ & $\begin{array}{l}\text { Technical } \\
\text { Manager } \\
(23 \%)\end{array}$ & $\begin{array}{l}\text { Applied Re- } \\
\text { search (19\%) }\end{array}$ & $\begin{array}{l}\text { Test and } \\
\text { Evaluation } \\
(9 \%) \\
\text { Basic Re- } \\
\text { search (9\%) }\end{array}$ & $\begin{array}{l}\text { Admin. Man- } \\
\text { ager (7\%) } \\
\text { Design (7\%) }\end{array}$ & $\begin{array}{l}\text { Data Analy- } \\
\text { sis (6\%) } \\
\text { Other (6\%) }\end{array}$ & $\begin{array}{l}\text { Information } \\
\text { Professional } \\
(3 \%)\end{array}$ \\
\hline
\end{tabular}

Table 3.

indicate the one or two disciplines and work roles that best characterized his or her work. A summary of the dominant ones is provided in Table 3. Other STI user demographic data presented to the STI Council were:

- The respondents had an average of 16 years associated with NASA

- Approximately two-thirds of respondents were NASA employees. The remaining onethird were NASA contractors

- Almost 90 percent of the respondents worked on a NASA Center (not off-site)

- The distribution of higher-level education degrees was:

$$
\begin{aligned}
& \text { - BS: } 38 \text { percent } \\
& \text { - MS: } 32 \text { percent } \\
& \text { - PhD: } 23 \text { percent. }
\end{aligned}
$$

Other data were collected on respondents' participation in training and course work, but not incorporated into the Council briefing.

\section{B. Use of NASA STI Publications Assistance}

\section{Services}

In order to reflect the STI Council's directive to understand the needs of frequent and infrequent users, the STI Team examined the frequency of use of STI services or products. quent user category. Two areas of interest relevant to this question were the disciplines these three groups represented, and their suggestions for improving the service. Table 4 provides these data in order of descending frequency of response.

Three major reasons that respondents gave for not using NASA STI Publications Assistance Services were: they did not publish in the course of their work (55 percent), did not know this service was available (19 percent), or they used desktop or other in-house publishing capabilities ( 9 percent). For those users who did use this service, the majority were usually very satisfied with the timeliness, ease of use, and results.

\section{Use of NASA STI Resources}

This section of the survey instrument determined how users located and obtained STI. One way was to ask someone, another was to consult published materials, and a third was to retrieve information from electronic resources.

\section{People}

All user types ranked their coworkers as the primary "people" resource they tumed to when locating STI. This is understandable since colleagues tend to be working in similar or re- 
lated endeavors and can give immediate ideas and guidance. For both moderate and infrequent them in a database or distribute them on CDROM. Others suggested that their existence be

\begin{tabular}{|c|c|c|c|}
\hline & Frequent User & Moderate User & Infrequent User \\
\hline Disciplines & $\begin{array}{l}\text { - Earth Science } \\
\text { - Flight Systems } \\
\text { - Materials and Struc- } \\
\text { tures } \\
\text { - Aeronautic Engineer- } \\
\text { ing } \\
\text {-Physics } \\
\end{array}$ & $\begin{array}{l}\text { Other, e.g., Mathemat- } \\
\text { ics, Ops Research, Fluid } \\
\text { Systems } \\
\text { - Aerospace Engineer- } \\
\text { ing } \\
\text { - Materials and Struc- } \\
\text { tures } \\
\end{array}$ & $\begin{array}{l}\text { - Aeronautic Engineer- } \\
\text { ing } \\
\text { - Other } \\
\text {. Computer or Informa- } \\
\text { tion Science } \\
\text { - Electrical Engineering }\end{array}$ \\
\hline $\begin{array}{l}\text { Suggestions for Im- } \\
\text { proving Service }\end{array}$ & $\begin{array}{l}\text { - Publicize } \\
\text { - Faster turnaround } \\
\text { - Improve customer fo- } \\
\text { cus }\end{array}$ & $\begin{array}{l}\text { - Faster turnaround } \\
\text { - No opinion } \\
\text { - Improve quality } \\
\text { - Upgrade resources } \\
\text { - Easier access to ser- } \\
\text { vice } \\
\text { - Improve customer fo- } \\
\text { cus } \\
\text { - Publicize } \\
\text { - Lower cost }\end{array}$ & $\begin{array}{l}\text { - No opinion } \\
\text { - Publicize } \\
\text { - Upgrade resources } \\
\text { - Faster turnaround } \\
\text {-Easier access to service }\end{array}$ \\
\hline
\end{tabular}

Table 4.

users of the NASA STI Program, the next "people" resource was librarians at the Center. For frequent users, experts who worked at the Center was their next choice.

\section{Brinted Materials}

There was a low use rate for NASAgenerated STI subscription publications such as Scientific and Technical Aerospace Reports (STAR), Selected Current Aerospace Notices (SCAN), International Aerospace Abstracts, and continuing or custom bibliographies. These publications tended to be used two to four times a year. For those individuals who did review them, over one-third indicated that such publications kept them current in their field. For the users, almost 20 percent stated that these NASA publications allowed them to locate additional reference material. When asked why they did not use these publications, 40 percent of the respondents said that they were unaware that the publications existed. Over 20 percent indicated that they did not need them, and almost 15 percent felt that NASA subscription publications were not useful or relevant. To improve use of these publications, respondents suggested that NASA automate them, i.e., put publicized better and subject coverage increased.

NASA research reports, such as Technical Reports, Conference Publications, Technical Papers, Technical Memorandums, Reference Publications, and Contractor Reports, were used three to six times per year. For individuals who used this group of printed STI materials, 25 percent indicated that they provided background source information while 17 percent stated that these reports provided useful technical data. Equally important was how research reports keep users current in their fields and provide information on related work. When asked why they did not use these research publications, infrequent users responded that there was no need for them, or the materials did not apply to their work. The next reason given by infrequent users was that they were unaware these research reports were available. Almost one-quarter of the users of the research reports felt they were adequate. Others suggested they be made available electronically and the overall quality improved.

Use for STI publications produced outside NASA, e.g., journals, textbooks, handbooks/standards, and trade magazines, was high 
with a range of 12 to 30 uses per year. These materials were obtained through a variety of means including direct procurement, requests made through the Center library, or procured by a services support contractor.

\section{Electronic Resources}

These resources, which encompass RECON, ARIN, commercial database resources, Internet, and local services such as a work group's bulletin board system, are being used a couple of times each month on average. Of interest to the STI Council was use of RECON. Among frequent, moderate, and infrequent users of electronic resources, all tended to do their RECON searching at the Center library either on their own or with a librarian's assistance. Even frequent users of electronic resources indicated that the reason they did not use RECON was that they were unaware of it. The moderate and infrequent user groups, in additional responses as to why they did not use RECON, indicated on overall need for awareness and training. There are a number of RECONrelated questions posed in the survey instrument combined with information on use of other electronic resources. The data are resident in the FoxPro $^{\mathrm{TM}}$ database, but were not analyzed for the STI Council briefing.

\section{Respondents' Suggestions for NASA STI Brogram Improvements}

There were four text responses as the last section of the survey that requested opinions on the overall NASA STI Program. The first question asked how the respondent found out about the STI Program. Over two-thirds indicated they found out from library advertisements and other awareness activities initiated by the Center's library staff. Almost one-quarter of the respondents learned of the STI Program as a result of participating in the survey. Approximately 20 percent had become users of the STI Program after learning about it from coworkers or by wordof-mouth. Still, another 10 percent were unaware of the Program.

The following suggestions were provided in response to the question "what improvements or enhancements to current NASA STI products and services would you like to see?" in order of importance:

- Distribute a users guide on the NASA STI Program ( 30 percent)

- Provide access to various products and services from a user's PC (19 percent)

- Provide user training (7 percent)

- Work toward a more timely publication process ( 7 percent)

- The STI Program is fine as it is (5 per-

cent)

Next the survey asked what new products or services could be offered by the NASA STI Program. These suggestions, in order of importance, were:

- Increase awareness of the NASA STI Program (26 percent)

- Provide access to various products and services from a user's PC (22 percent)

- Don't have a suggestion (15 percent)

- Improve the publications and publishing process (10 percent)

- Distribute NASA documents on CD. ROM (8 percent)

- The STI Program is fine as it is ( 3 percent).

Finally, a significant number of respondents, over 250 , indicated a willingness to participate in a group for defining future NASA STI products and services. Many provided useful suggestions for how such a group could be organized.

\section{Presentation before the SII Council}

On May 6, 1992 a briefing on the survey was provided to the STI Council. In addition to the data analysis directed toward responding to questions and issues raised by the Council the year before, several major conclusions were provided:

- Frequent users of the STI Program tend to be in "traditional" NASA research discplines, i.e., involved in aerospace engineering, basic research, or technical management. Frequent users typically have been with NASA for a Ionger time and perhaps have had more overall exposure to the STI Program. 
- Infrequent or nonusers tend to be in management, administration, or "traditional" NASA applied disciplines. Their work roles tend to be applied research, design, and development, rather than basic research. Often these users have been with NASA fewer than five years.

- Most of the potential user market is unaware of the Program's products or services, or the utility of those products or services to them.

- Convenience and flexibility of access are key in expanding use of both publication assistance services and STI resources.

- A regular and continuing dialog with user groups is required to understand their access priorities and to better meet their needs.

Finally, the briefing delivered three recommendations to the STI Council:

- Continue and broaden user outreach efforts to applied disciplines with particular emphasis on newer NASA staff.

- Plan improvements to the STI Program based on survey data. For example, since staff tend to rely on coworkers for identifying and providing access to STI, facilitate access to those coworkers through STI Program services and resources.

- Call upon volunteers who indicated a willingness to participate in an STI users' group and use them to form focus groups. These groups can prioritize suggested improvements and ways to achieve their implementation.

\section{Follow-up Activities and Ongoing Analysis}

Data collected from the survey are extensive and revealing. Not all the data was used to report to the STI Council. The NASA STI Program has begun an active program to continue to analyze and review the data in response to specific questions as well as assist in examining continuing issues.

Specific projects have been initiated to address the recommendations made to the STI Council. To increase awareness of the STI Pro- gram, the User Outreach section has been restructured and expanded to include representatives to support specific NASA Program Offices. These representatives are employing a market approach to seek out suppliers of STI in order to obtain the documents. They also identify opportunities for the Program to support their information needs, such as database building efforts, specialized bibliographies, and distribution of electronic media. The goal of the User Outreach section is to be proactive with the Program Offices in order to make them aware of the products and services available to meet their information needs.

To facilitate access to sources of STI, including peers (an important "people" resource revealed by the survey), the NASA Access Mechanism (NAM) prototype has incorporated methods for locating and communicating with peers as an integral part of the system design. NAM will be fielded for the next six months to end users within NASA to obtain feedback on the beta version of the system.

A user group is being chartered with representatives from the NASA STI community. The User Outreach section has contacted the volunteers that were identified in this user survey. Two teleconferences have been held to discuss the user group. A charter is under development.

The user survey database is also being used by teams who are addressing specific areas of development within the STI Program, such as acquisitions, to better define user requirements and identify potential participants in focus groups. 


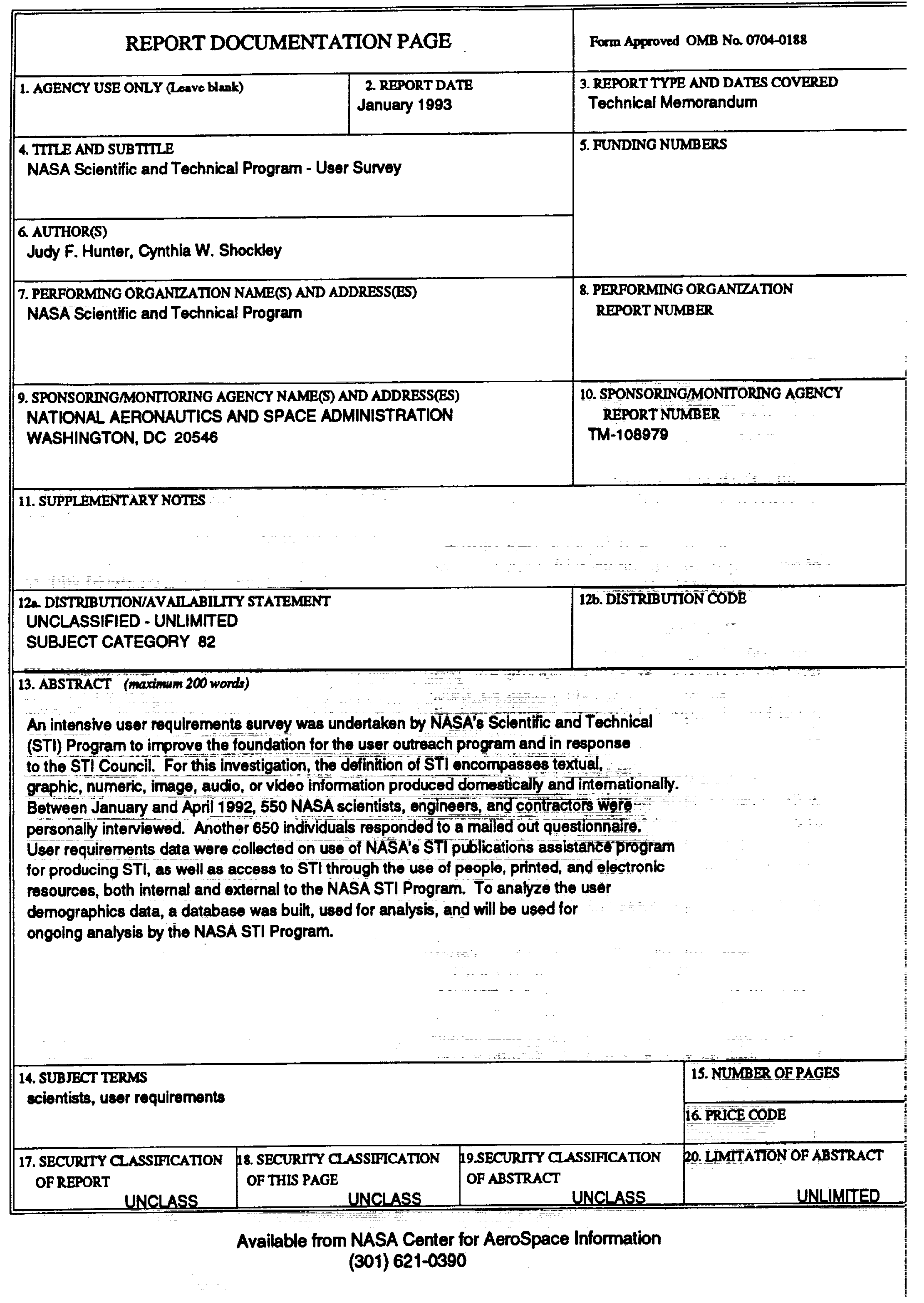

